\title{
Adolescents' Perceptions of Privacy Invasion in Reaction to Parental Solicitation and Control
}

\author{
Skyler T. Hawk \\ University of Amsterdam \\ William W. Hale III \\ Quinten A. W. Raaijmakers \\ Wim Meeus \\ Utrecht University, the Netherlands
}

Following suggestions from prior research, this 2-wave longitudinal study examined whether parental solicitation and control influenced adolescents' later perceptions of privacy invasion. Data from 307 Dutch adolescents were tested with structural equation modeling (SEM). Differences in adolescents' invasion perceptions were examined in terms of gender and the quality of interactions with parents. Parental control influenced later invasion perceptions among adolescents reporting higher quality interactions with parents, particularly among males. Parental solicitation also predicted perceptions of invasion. Results are discussed in terms of Kerr and Stattin's (2000) reinterpretation of parental monitoring, gender differences, the dialectical tension between openness and closedness in family relationships, and implications for adolescent-parent privacy negotiations.

Keywords: privacy invasion; parental monitoring; intrusive parenting; adolescent-parent relationships

$\mathrm{n}$ individual's ability to experience a sense of privacy is likely to be
important at every stage of life (Margulis, 2003; Newell, 1995; Petronio,

Authors' Note: The authors would like to thank Professor Catrin Finkenauer of Free University Amsterdam and Professor Sandra Petronio of the Indiana University Center for Bioethics for their feedback on earlier drafts of this article. Correspondence should be directed to Skyler T. Hawk, Department of Social Psychology, University of Amsterdam. 
2002). However, the contexts that determine privacy rules are not equally applicable to people of different ages, because attitudes, competencies, and social roles change over time (Laufer \& Wolfe, 1977; Petronio, 2002). Importantly, personal "relationships do not follow an inexorable trajectory toward increasing intimacy but rather cycle between periods of accessibility and inaccessibility" (Burgoon et al., 1989, p. 132). Early adolescence likely represents a period of heightened inaccessibility, as a major task for this stage is to begin individuating from parents (Youniss \& Smollar, 1985). Despite these moves toward adulthood, parents wish to remain informed about their children's lives and may be surprised when they hear the words, "Stay out of my business!" The current research investigates whether early adolescents' perceptions of privacy invasion are linked to parents' day-to-day monitoring behaviors.

Investigations on invasions of privacy raise interesting questions about how parents obtain information about adolescents, as do recent reinterpretations of parental monitoring practices (Kerr \& Stattin, 2000; Stattin \& Kerr, 2000). Previous studies on privacy invasion in families have often utilized college-aged samples, have focused on rather extreme acts of privacy invasion, and have usually relied on cross-sectional data (e.g., Burgoon et al., 1989; Petronio, 1994). Few studies have examined invasion feelings in reaction to parents' everyday information gathering, or the role of the adolescent-parent relationship in forming such perceptions. The present investigation addresses these gaps in the literature.

Operational definitions of privacy are varied (see Margulis [2003] and Newell [1995] for thorough reviews), but one consistent theme has been that individuals desire to manage access to their personal information. Wolfe and Laufer (1974) noted that controlling access to information becomes increasingly integral to children's privacy conceptions and is a dominant theme by early adolescence. Petronio's (2002) communication privacy management (CPM) theory suggests that adolescents have certain expectations about which information falls under their personal jurisdiction and claim the right to control its access. Youth and parents can disagree, however, on which issues constitute this personal sphere. In particular, parents may be unwilling to relinquish informational control as quickly as adolescents would like (Collins, Laursen, Mortensen, Luebker, \& Ferreira, 1997; Smetana, Metzger, Gettman, \& Campione-Barr, 2006).

CPM theory suggests that feelings of privacy invasion can occur when two or more individuals disagree over the limits of information co-ownership (Petronio, 2002). These disagreements become apparent during episodes of privacy invasion. Perceptions of privacy violation are subject to individual differences, and people may not even recognize that others view their behav- 
ior as intrusive (Petronio, 1994, 2002). These mismatched perceptions create "boundary turbulence," which in turn motivates a renegotiation of privacy rules. This cycle of expectancy violation and realignment can occur repeatedly within relationships (Caughlin \& Petronio, 2004; Collins \& Luebker, 1994). Parents and early adolescents must continually adjust their ideas about the relationship, suggesting that this period is rife with opportunities for both privacy violation and renegotiation.

As children enter early adolescence, they begin to fortify privacy boundaries with parents. They increasingly use physical barriers (e.g., closed doors) and enforce established privacy rules (e.g., knocking) to define their personal space (Parke \& Sawin, 1979; Petronio, 1994). Early adolescents also begin to spend more time away from direct supervision, which provides new opportunities for selectively sharing information with parents (Kerr, Stattin, \& Trost, 1999; Larson, Richards, Moneta, Holmbeck, \& Duckett, 1996). Furthermore, youths' peers begin to replace parents on many social fronts associated with privacy, including seeking and providing social support and disclosing personal issues (Hunter, 1985). Adolescents' continuing social-cognitive development also promotes changes in which issues they feel they must share with parents. Beliefs that parents deserve knowledge about free-time activities and peer associations appear to decline over time (Laird, Pettit, Dodge, \& Bates, 2003). Adolescents also begin to feel less obligated to disclose risk behaviors or to discuss moral issues (e.g., lying, keeping promises), perhaps because mutually agreed-upon expectations for these behaviors are already in place (Smetana \& Daddis, 2002; Smetana et al. 2006).

CPM theory emphasizes a dialectical tension between openness and closedness that characterizes privacy negotiations in close relationships. Youth must balance the desire to maintain familial relationships with their increasing needs for privacy (Caughlin \& Petronio, 2004; Petronio, 2002). Parents must encourage adolescents' individuation while still ensuring adequate adjustment in the moral, prudential, and social-conventional domains (Smetana et al., 2006). A compromise may be reached through parents' efforts to stay informed about their children's behavior (Steinberg, 2002), previously termed parental monitoring. Kerr and Stattin (2000; Stattin \& Kerr, 2000) have suggested two active parental monitoring strategies. First, parents may ask direct questions about the youth's activities and whereabouts, labeled solicitation. Second, parents may also set explicit rules about being informed before adolescents engage in certain activities, termed parental control. Stattin and Kerr (2000) focused solely upon behavioral control, as opposed to psychological control tactics such as criticism or love withdrawal (cf. Barber, 1996). 
Monitoring behaviors are not equivalent in all families, and the quality of adolescent-parent interactions may moderate these processes. Adolescents' reports of "bad" relations with mothers and fathers (as defined by higher levels of conflict and negative emotionality) are associated with lower levels of parental solicitation, and poor relations with fathers are additionally associated with lower levels of parental control (Kerr \& Stattin, 2000). Accordingly, we predicted that adolescents reporting more positive interactions with parents would also report higher levels of both monitoring behaviors (Hypothesis 1). Conversely, adolescents' feelings of trust and relationship satisfaction appear to decline in the wake of privacy invasion experiences (Petronio, 1994). This suggests that youth who perceive lower quality interactions with parents should report stronger feelings of privacy invasion (Hypothesis 2).

Researchers have traditionally held positive views of parental monitoring (see Stattin \& Kerr [2000] for a thorough review). However, it does not appear that parents' active monitoring behaviors hold direct links to youths' better adjustment (Kerr \& Stattin, 2000; Waizenhofer, Buchanan, \& Jackson-Newsom, 2004). In fact, Kerr and Stattin (2000) found that some active monitoring strategies might actually be detrimental for adolescents. Specifically, parents' behavioral control influenced adolescents' feelings of being controlled by external forces, which in turn was associated with poorer psychological adjustment. Stattin and Kerr's (2000) concept of parental control suggests a denial of adolescents' power to make certain (non)disclosure choices about their own lives. Given the references to managing informational access found in various definitions of privacy (e.g., Margulis, 2003; Newell, 1995; Petronio, 2002), adolescents may view such disclosure rules as intrusive. Kerr and Stattin (2000) made an additional (untested) suggestion that parents' solicitations about the same topics might also be seen as privacy violations. We addressed these issues, predicting both parental solicitation and control to hold longitudinal associations with feelings of privacy invasion (Hypothesis 3 ).

Parental behaviors may take on different meanings within the contexts of different adolescent-parent relationships. Specifically, we expected the quality of adolescent-parent interactions to moderate the links between parental monitoring behaviors and adolescents' perceptions of privacy invasion. More openness with parents occurs when relationship quality is high (e.g., Finkenauer, Engels, Branje, \& Meeus, 2003; Smetana et al., 2006). Higher relationship quality also predicts adolescents' stronger beliefs that parents deserve knowledge about their activities (Laird et al., 2003). However, this need not imply adolescents' appreciation or acceptance of all 
monitoring strategies. In particular, parents may communicate mixed messages when the relationship is good, yet they continue to make many explicit rules regarding disclosure and conduct (Pomerantz \& Eaton, 2000; Pomerantz \& Ruble, 1998). Monitoring may be interpreted simultaneously as a sign of parental interest and as a message that the child is incompetent. Adolescents who feel generally positive about their relationships with parents thus may eventually come to resent monitoring, because it conflicts with their own expectancies about parental trust and responsible selfdisclosure (Collins \& Luebker, 1994; Kerr et al., 1999). In contrast, these expectancy violations may not occur in the context of less satisfactory interactions. Thus, participants reporting a higher quality of interactions with parents were expected to show stronger longitudinal associations from solicitation and control to feelings of privacy invasion (Hypothesis 4).

Finally, adolescents' gender could moderate their interpretations of parental monitoring. Though Stattin and Kerr's (2000) research found no differences in parents' knowledge about male or female youth, females reported greater parental solicitation and control. However, females might also differently define what constitutes acceptable levels of parental monitoring and thus show stronger or weaker associations, compared to males, between reports of monitoring behaviors and invasion perceptions. Past studies have not examined differences in male and female adolescents' interpretations of parental monitoring, so no a priori hypotheses were made with regard to gender.

\section{Method}

\section{Participants}

Participants were 328 Dutch youth participating in the CONflict And Management Of RElationships (CONAMORE) project, an ongoing longitudinal study. At the time of initial data collection (2002), participants ranged in age from 12 to 15 years $(\bar{X}=13.23, S D=0.51)$; the modal age was 13 years $(71 \%)$. At the second assessment (2004), participants ranged from 14 to 17 years $(\bar{X}=15.46, S D=0.55)$. Adolescents mostly identified as native Dutch (98.7\%), with 2 indicating another ethnicity (i.e., Turkish and Moroccan) and 2 providing no information. Most youth (98\%) lived with both parents, with the rest of the sample $(n=5)$ being divided among other family structures (e.g., mother only, mother and stepfather, etc.) and 1 participant giving no information. At Time 1, approximately $50 \%$ of the adolescents were preparing for university, $35 \%$ were preparing for higher education, 
and $15 \%$ were preparing for blue-collar work. The educational level of the fathers and mothers could be differentiated as $27.3 \%$ and $32.0 \%$ low-tomiddle and $72.7 \%$ and $68.0 \%$ high, respectively.

Relative mean substitution (RMS; Raaijmakers, 1999) was used to impute participants' missing scores, as long as participants responded to a vast majority of the items on each scale at each measurement wave. Prior to the RMS procedure, the percentage of missing data for all items ranged from $1.5 \%$ to $5.5 \%$. Following RMS, complete data were available for 307 youths (151 males and 156 females). Twenty-one participants (6\%) were excluded because at least one variable, at either time point, could not be imputed. These individuals showed no differences from the larger sample for gender, family structure, child and parental education, or age.

\section{Measures}

Confirmatory factor analyses (CFAs) with maximum likelihood estimation (MLE) were conducted separately for each administration of each measure, using the Amos program (version 5.0; Arbuckle, 2003). In some cases, item errors were allowed to correlate for indicators that were similar in content.

Parental solicitation. Stattin and Kerr (2000) used five items on a 5point Likert scale $(1=$ never, $5=$ always $)$ to measure parental solicitation. This scale, translated into Dutch, was used in the present study. A CFA revealed that two items in the original measure (how often parents spoke to the parents of adolescents' friends and how often parents initiated conversations with adolescents' friends) showed problematic factor loadings (both items $<.35$ in Wave 1 , one item $<.27$ in Wave 2 ). All other items, pertaining to how often parents initiated direct conversations with children about their activities, loaded well on one factor in both Waves (loadings $\geq .51$ ). A second model was tested in which these two items were added as a separate dimension. ${ }^{1}$ The other four items again loaded well on one factor (loadings $\geq$ .49 ), and the models showed acceptable fits, Wave 1: $\chi^{2}(8)=10.73$, $p=.217, \mathrm{CFI}=.99$, normed fix index $(\mathrm{NFI})=.96$, adjusted goodness-of-fit index $(\mathrm{AGFI})=.97$; Wave $2: \chi^{2}(8)=14.76, p=.064, \mathrm{CFI}=.98, \mathrm{NFI}=.95$, AGFI $=.96 .^{2}$ The two problematic items were omitted from further analyses. The alpha scores of this revised measure (.69 and .70 , respectively) were comparable to past research (Kerr \& Stattin, 2000).

Parental control. Stattin and Kerr (2000) used six items on a 5-point Likert scale $(1=$ never, $5=$ always $)$ to measure parental control. Items questioned 
participants about the extent to which they had to ask permission from and/or tell parents about their free time activities and peer associations. A Dutch translation of this scale was used. In CFA one original item (seeking permission from parents before leaving the house on a weekday evening) loaded poorly in both waves (Wave $1=.24$; Wave $2=.30$ ). All other measures loaded satisfactorily on one dimension for both waves (loadings $\geq$ 42). Fit statistics for the revised models were acceptable, Wave 1: $\chi^{2}(5)=$ $19.55, p=.002, \mathrm{CFI}=.97, \mathrm{NFI}=.96, \mathrm{AGFI}=.93$; Wave $2: \chi^{2}(5)=4.77, p$ $=.445, \mathrm{CFI}=1.00, \mathrm{NFI}=.99, \mathrm{AGFI}=.98$. This revised measure demonstrated good reliability (Wave $1 \alpha=.80$, Wave $2 \alpha=.86$ ).

Perceived privacy invasion. A Dutch translation of the Intrusiveness subscale of the Level of Expressed Emotion (LEE) questionnaire (Hale, Raaijmakers, Gerlsma, \& Meeus, 2007) measured perceptions of parental privacy invasion. This is a seven-item measure, arranged on a 4-point Likert scale $(1=$ untrue, $4=$ true $)$. The items are as follows: My parents . . Are always nosing into my business; Have to know everything about me; Are always interfering; Butt into my private matters; Often check up on me to see what I'm doing; Insist on knowing where I'm going; Don't pry into my life (reversed). Items loaded on one dimension in CFA (Wave $1 \geq .41$, $\alpha=.84$; Wave $2 \geq .44, \alpha=.87$ ) and fit statistics were satisfactory, Wave 1 : $\chi^{2}(13)=18.08, p=.155$, CFI $=.99$, NFI $=.98$, AGFI $=.96$; Wave 2 : $\chi^{2}(13)=37.71, p<.001, \mathrm{CFI}=.98, \mathrm{NFI}=.96, \mathrm{AGFI}=.93$.

Adolescent-parent interaction quality. A subscale of the Network of Relationship Inventory (NRI; Furman \& Buhrmester, 1985) assessed adolescents' perceptions of positive, supportive interactions with mothers and fathers, separately for each parent. This consisted of 12 items on a 5-point scale $(1=$ little or none, 5 = the most), pertaining to adolescents' perceptions of democratic family style, autonomy-supportive messages, and affection from parents. For mothers, all items loaded on one dimension in Wave 1 (loadings $\geq .40, \alpha=.87$ ) and Wave 2 (loadings $\geq .48, \alpha=.90$ ). These models had acceptable fits, Wave $1: \chi^{2}(50)=95.58, p<.001$, CFI $=.97$, $\mathrm{NFI}=.93, \mathrm{AGFI}=.92$; Wave $2: \chi^{2}(48)=120.46, p<.001, \mathrm{CFI}=.96, \mathrm{NFI}=$ .94 , AGFI $=.89$. Similar results were found for fathers in Wave 1 (loadings $\geq .42, \alpha=.90$ ) and Wave 2 (loadings $\geq .41, \alpha=.92$ ). The models passed minimum acceptability thresholds, Wave $1: \chi^{2}(49)=124.31, p<.001, \mathrm{CFI}=$ $.96, \mathrm{NFI}=.94$, AGFI $=.90 ;$ Wave $2: \chi^{2}(46)=142.54, p<.001, \mathrm{CFI}=.96$, $\mathrm{NFI}=.94 ; \mathrm{AGFI}=.88$. 


\section{Data Collection Procedures}

Trained research assistants administered the NRI during participants' homeroom study period. All other measures were administered and completed at participants' homes on a separate day. Students and their parents received written information and provided informed consent. Less than $1 \%$ refused participation. Consent was also obtained from all schools. Students absent on the day of school testing were not assessed. Verbal and written instructions were given prior to testing in both locations. Annual assessments $(2002,2003$, and 2004) of solicitation, control, and interaction quality were gathered. Perceptions of privacy invasion were assessed biannually (2002 and 2004).

\section{Statistical Analyses}

The biannual assessment of privacy invasion allowed for analyses based on two time points. For each respective assessment, we calculated mean scores for Wave 1 (2002) and Wave 2 (2004) reports of solicitation, control, and privacy invasion by averaging the item scores. To examine the moderating effect of interaction quality, we computed an NRI mean score by aggregating separate reports on each parent at each time point and then forming a total score by calculating the mean of the mother and father variables (Stattin \& Kerr, 2000). We chose this procedure because all other measures referred only to "parents" and not to mothers or fathers, separately. This resulted in one general NRI score for each participant $(\bar{X}=3.44, S D=$ .61 ), ranging from 1.37 to 4.92 . The sample size excluded the use of NRI scores as a continuous moderator in SEM, so a median split was used. Adolescents in the lower $50 \%$ of mean scores $(\leq 3.521 ; n=153)$ were assigned to a Lower Quality Interactions group, and the upper 50\% (> 3.521; $n=154)$ to a Higher Quality Interactions group.

To examine the within-subjects development of variables over time, we performed separate repeated-measures ANOVAs for each measure, with gender and interaction quality as between-subjects factors. Additionally, we carried out a repeated-measures analysis for adolescents' NRI reports, on a continuous scale, at each wave. This was done to examine relationship change over time and to provide additional information about the reliability of the median split procedure. We then repeated these analyses while including as a covariate adolescents' age in Wave 1 (2002).

On the basis of these data, we tested the theoretical model (see Figure 1) for the total sample of 307 participants, using MLE. First, three paths represented the relative variable stabilities over time. Second, the relations 
between solicitation, control, and perceived invasion were specified in cross-lagged paths. As the development of monitoring behaviors was not the main focus of the study, we did not included cross-paths between solicitation and control. Finally, correlations represented mutual influences between variables at each measurement point.

Next, we performed a two-group SEM analysis for the Higher and Lower Quality groups. When significant differences in the strength of a path exist between groups, allowing that path to vary should result in improved model fit. Successive model adjustments are outlined in Table 3. Beyond the initial model (Model 0), equality constraints were successively removed for the cross-lagged paths between Control and Invasion (Model 1), the cross-paths between Solicitation and Invasion (Model 2), the three stability paths (Model 3), the covariances (Model 4), and all remaining paths (Model 5). Freeing equality constraints improved the model when the chi-square statistic was significantly smaller $(p<.05)$ than the previous value. Critical ratios for estimated parameters, for each path, revealed the significant between-groups differences. For a two-tailed test, critical ratios above 1.96 suggest group differences at $p<.05$, values above 2.58 suggest $p<.01$, and values above 3.30 indicate $p<.001$. Similar analyses were then performed on a two-group model comparing males and females and on a four-group model of interaction quality and gender.

\section{Results}

\section{Development in Mean Scores}

The means, standard deviations, and correlations for all SEM model variables can be viewed in Table 1. Results of the initial repeated-measures tests are shown in Table 2. The Higher Quality group reported more solicitation and control, and less perceived invasion, compared to the Lower Quality group. Females reported more solicitation and control than males, but equal levels of invasion and interaction quality. While there was no change in parental solicitation over time, control and perceived invasion declined over time. Additionally, a Gender $\times$ Time interaction qualified the effect of time upon control; males reported a sharper decline $\left(\bar{X}_{\text {Time } 1}=3.42\right.$, $\left.S D=0.07 ; \bar{X}_{\text {Time } 2}=2.80, S D=0.07\right)$ than females $\left(\bar{X}_{\text {Time } 1}=3.51, S D=0.07\right.$; $\left.\bar{X}_{\text {Time } 2}=3.29, S D=0.07\right)$. Interaction quality also declined over time for both groups, and youth in the Higher Quality group reported a higher quality of interactions with parents. 


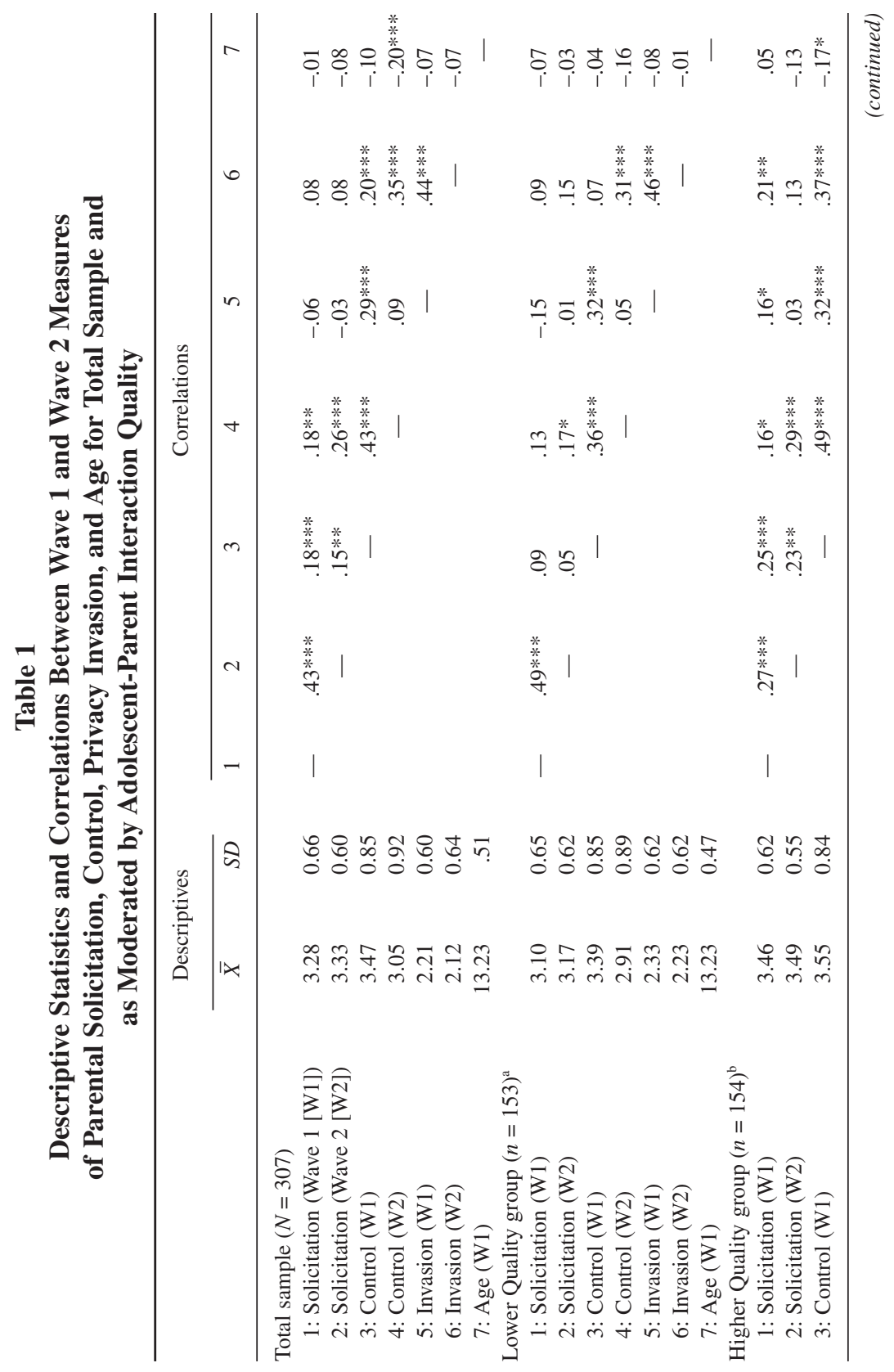




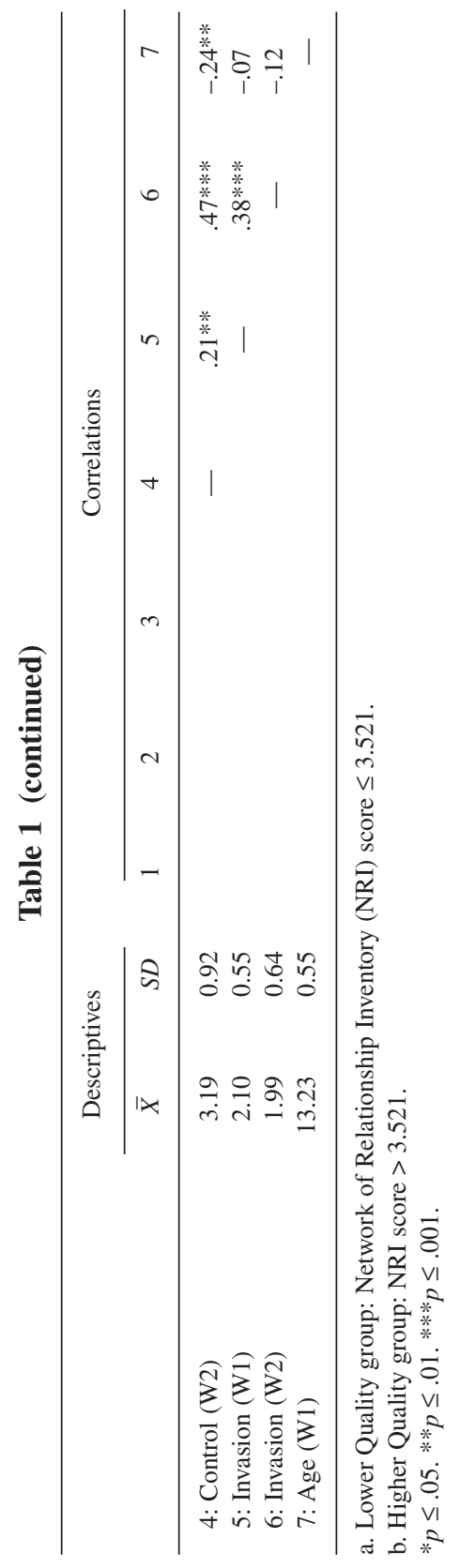


Table 2

Development of Adolescent-Reported Parental Solicitation, Parental Control, Perceived Privacy Invasion, and Adolescent-Parent Interaction Quality (Repeated-Measures ANOVAs)

\begin{tabular}{|c|c|c|c|c|c|c|}
\hline & $N$ & $\bar{X}$ & $S E$ & $d f$ & $F$ & $\eta^{2}$ \\
\hline \multicolumn{7}{|l|}{ Parental Solicitation } \\
\hline \multicolumn{7}{|l|}{ Between subjects } \\
\hline \multicolumn{7}{|l|}{ Interaction quality } \\
\hline Lower quality & 153 & 3.04 & .04 & & & \\
\hline Higher quality & 154 & 3.29 & .04 & 1 & $15.93 * * *$ & .05 \\
\hline \multicolumn{7}{|l|}{ Gender } \\
\hline Male & 151 & 3.08 & .05 & & & \\
\hline Female & 156 & 3.26 & .04 & 1 & $8.41 * *$ & .03 \\
\hline $\begin{array}{l}\text { Gender } \times \text { Interaction } \\
\text { Quality }\end{array}$ & & & & 1 & 1.33 & .00 \\
\hline Error & & & & 303 & $(.59)$ & \\
\hline \multicolumn{7}{|l|}{ Within subjects } \\
\hline \multicolumn{7}{|l|}{ Time } \\
\hline Wave 1 & 307 & 3.14 & .04 & & & \\
\hline Wave 2 & 307 & 3.19 & .04 & 1 & 1.48 & .01 \\
\hline $\begin{array}{l}\text { Interaction Quality } \\
\quad \times \text { Time }\end{array}$ & & & & 1 & .04 & .00 \\
\hline Gender $\times$ Time & & & & 1 & .08 & .00 \\
\hline $\begin{array}{l}\text { Interaction Quality } \\
\quad \times \text { Gender } \times \text { Time }\end{array}$ & & & & 1 & .75 & .00 \\
\hline Error & & & & 303 & $(.26)$ & \\
\hline \multicolumn{7}{|l|}{ Parental Control } \\
\hline \multicolumn{7}{|l|}{ Between subjects } \\
\hline \multicolumn{7}{|l|}{ Interaction quality } \\
\hline Lower quality & 153 & 3.16 & .06 & & & \\
\hline Higher quality & 154 & 3.35 & .06 & 1 & $4.89 *$ & .02 \\
\hline \multicolumn{7}{|l|}{ Gender } \\
\hline Male & 151 & 3.11 & .06 & & & \\
\hline Female & 156 & 3.40 & .06 & 1 & $12.06 * * *$ & .04 \\
\hline $\begin{array}{l}\text { Gender } \times \text { Interaction } \\
\text { Quality }\end{array}$ & & & & 1 & .03 & .00 \\
\hline Error & & & & 303 & $(1.06)$ & \\
\hline \multicolumn{7}{|l|}{ Within subjects } \\
\hline \multicolumn{7}{|l|}{ Time } \\
\hline Wave 1 & 307 & 3.46 & .05 & & & \\
\hline Wave 2 & 307 & 3.05 & .05 & 1 & $61.02 * * *$ & .17 \\
\hline $\begin{array}{l}\text { Interaction quality } \\
\times \text { Time }\end{array}$ & & & & 1 & .37 & .00 \\
\hline Gender $\times$ Time & & & & 1 & $14.22 * * *$ & .05 \\
\hline
\end{tabular}


Table 2 (continued)

\begin{tabular}{|c|c|c|c|c|c|c|}
\hline & $N$ & $\bar{X}$ & $S E$ & $d f$ & $F$ & $\eta^{2}$ \\
\hline $\begin{array}{l}\text { Interaction Quality } \times \\
\text { Gender } \times \text { Time }\end{array}$ & & & & 1 & .57 & .00 \\
\hline Error & & & & 303 & $(.43)$ & \\
\hline \multicolumn{7}{|l|}{ Privacy Invasion } \\
\hline \multicolumn{7}{|l|}{ Between subjects } \\
\hline \multicolumn{7}{|l|}{ Interaction quality } \\
\hline Lower quality & 153 & 2.28 & .04 & & & \\
\hline Higher quality & 154 & 2.05 & .04 & 1 & $15.80 * * *$ & .05 \\
\hline \multicolumn{7}{|l|}{ Gender } \\
\hline Male & 151 & 2.15 & .04 & & & \\
\hline Female & 156 & 2.18 & .04 & 1 & .40 & .00 \\
\hline $\begin{array}{l}\text { Gender } \times \text { Interaction } \\
\text { Quality }\end{array}$ & & & & 1 & .11 & .00 \\
\hline Error & & & & 303 & $(.53)$ & \\
\hline \multicolumn{7}{|l|}{ Within subjects } \\
\hline \multicolumn{7}{|l|}{ Time } \\
\hline Wave 1 & 307 & 2.21 & .03 & & & \\
\hline Wave 2 & 307 & 2.12 & .04 & 1 & $6.62 * *$ & .02 \\
\hline $\begin{array}{l}\text { Interaction Quality } \times \\
\text { Time }\end{array}$ & & & & 1 & .09 & .00 \\
\hline Gender $\times$ Time & & & & 1 & 1.66 & .00 \\
\hline $\begin{array}{l}\text { Interaction Quality } \times \\
\text { Gender } \times \text { Time }\end{array}$ & & & & 1 & .06 & .00 \\
\hline Error & & & & 303 & $(.22)$ & \\
\hline $\begin{array}{l}\text { Adolescent-Parent } \\
\quad \text { Interaction Quality }\end{array}$ & & & & & & \\
\hline \multicolumn{7}{|l|}{ Between subjects } \\
\hline \multicolumn{7}{|l|}{ Interaction quality } \\
\hline Lower quality & 153 & 3.09 & .03 & & & \\
\hline Higher quality & 154 & 3.94 & .03 & 1 & $604.21 * * *$ & .67 \\
\hline \multicolumn{7}{|l|}{ Gender } \\
\hline Male & 151 & 3.53 & .03 & & & \\
\hline Female & 156 & 3.50 & .02 & 1 & .87 & .00 \\
\hline $\begin{array}{l}\text { Gender } \times \text { Interaction } \\
\text { Quality }\end{array}$ & & & & 1 & .99 & .00 \\
\hline Error & & & & 303 & $(.18)$ & \\
\hline \multicolumn{7}{|l|}{ Within subjects } \\
\hline \multicolumn{7}{|l|}{ Time } \\
\hline Wave 1 & 307 & 3.60 & .02 & & & \\
\hline Wave 2 & 307 & 3.44 & .03 & 1 & $28.94 * * *$ & .09 \\
\hline $\begin{array}{l}\text { Interaction Quality } \times \\
\text { Time }\end{array}$ & & & & 1 & .44 & .00 \\
\hline
\end{tabular}


Table 2 (continued)

\begin{tabular}{|c|c|c|c|c|c|c|}
\hline & $N$ & $\bar{X}$ & $S E$ & $d f$ & $F$ & $\eta^{2}$ \\
\hline Gender $\times$ Time & & & & 1 & .13 & .00 \\
\hline \multicolumn{7}{|l|}{ Interaction Quality $\times$} \\
\hline Gender $\times$ Time & & & & 1 & .24 & .00 \\
\hline Error & & & & 305 & (.13) & \\
\hline
\end{tabular}

Note: Values enclosed in parentheses represent mean square errors. Lower Quality group: Network of Relationship Inventory (NRI) score $\leq 3.521(n=153)$; Higher Quality group: NRI score $>3.521(n=154)$.

$* p \leq .05 . * * p \leq .01 . * * * p \leq .001$.

When Wave 1 age was added as a covariate, main effects of time no longer existed for any measure $(p>.05)$. The interaction between sex and time for parental control remained significant, $F(1,302)=12.45, p<.001$, partial $\eta^{2}=.04$. Additionally, a significant between-subjects effect for age was noted for parental control, $F(1,302)=7.63, p<.01$, partial $\eta^{2}=.03$, where control decreased with age. Age effects were not significant for any other variables $(p>.05)$. All previously reported differences based on gender and interaction quality remained significant.

\section{Theoretical Model for the Total Sample}

Highly skewed data (values exceeding \pm 1.0 ) threaten the validity of results obtained from the MLE method in SEM (Jöreskog \& Sörbom, 1989). Skewness values fell within the acceptable range (from -.14 to -.49). Given the link between age and parental control found in the repeated-measures analyses, age at Wave 1 was linked to adolescents' Wave 1 and Wave 2 reports of control. Standardized coefficients and fit indices can be viewed in Figure 1. All three stability paths were significant. Additionally, participants who were older at Wave 1 experienced a significant reduction in parental control at Wave 2. No cross-lagged paths were significant. Fit statistics were acceptable.

Theoretical model moderated by adolescent-parent interaction quality. The multigroup analysis revealed an improvement from the initial model (Model 0) after freeing cross-lagged paths between parental control and invasion (Model 1). No other changes improved the fit, and Model 1 showed the lowest Akaike information criterion (AIC) value. Thus, Model 1 was retained. Comparison indices can be viewed in Table 3. Model fit statistics (see Figure 2) were satisfactory. 


\section{Figure 1}

Standardized Coefficients for the Model of Relationships Between Solicitation, Control, and Privacy Invasion for Entire Sample $(N=307)$

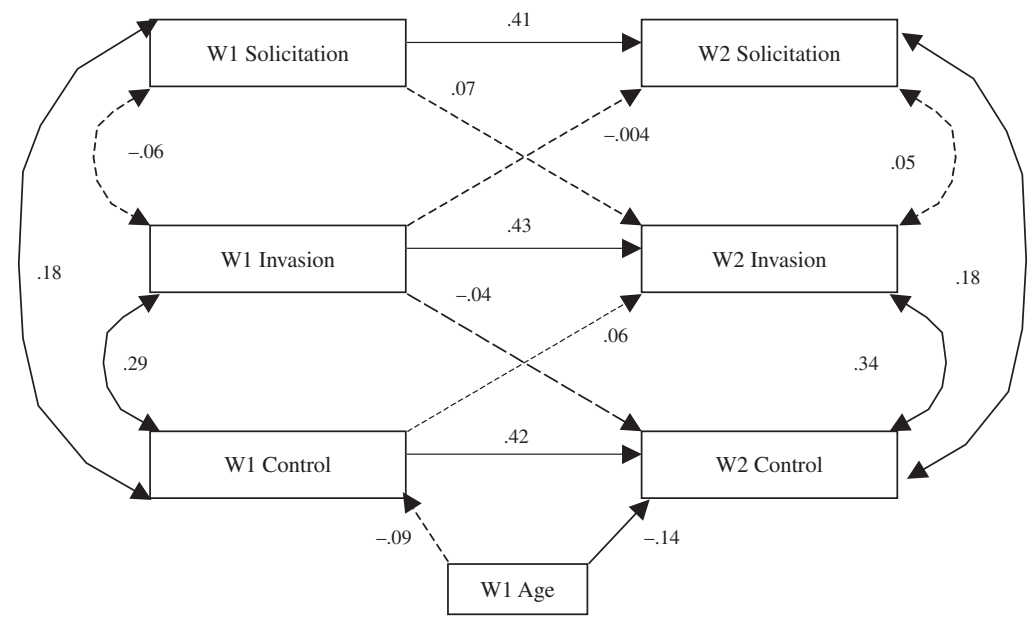

Note: Solid lines indicate statistically significant paths $(p<.01)$. W1 and W2 indicate Wave 1 and Wave 2. $\chi^{2}(6)=9.79, p=.213$, confirmatory fit index $(\mathrm{CFI})=.99$, adjusted goodnessof-fit index $(\mathrm{AGFI})=.96$, root mean square error of approximation $(\mathrm{RMSEA})=.05$.

Standardized coefficients for the final model can be seen in Figure 2. A significant group difference was found in the cross-lagged path from Wave 1 control to Wave 2 invasion (critical ratio $=2.96, p<.01$ ). The Higher Quality group showed stronger perceptions of invasion in response to parental control, while the Lower Quality group showed no relationship. The two groups also showed a significant difference from Wave 1 control to Wave 2 invasion (critical ratio $=2.36, p<.01$ ). Although this path was not significant for either group ( $p=.11$ and .13 , respectively), the Higher Quality group trended toward a positive association, while the Lower Quality group trended toward a negative association. Solicitation at Wave 1 predicted higher invasion at Wave 2 for both groups. As in the original model, all three stability paths were significant, and a main effect existed across groups for the path from Wave 1 age to Wave 2 control.

Theoretical model moderated by adolescent gender. An additional model compared males and females. Fit statistics for the initial model were 
Table 3

Multigroup Analyses of Structural Equation

Modeling (SEM) Model Fits ${ }^{\mathrm{a}}$

\begin{tabular}{|c|c|c|c|c|}
\hline \multirow[b]{2}{*}{ Model } & \multicolumn{4}{|c|}{ Fit Statistics } \\
\hline & $\chi^{2}$ & $d f$ & $\Delta \chi^{2}$ & $\begin{array}{c}\text { Akaike } \\
\text { Information } \\
\text { Criterion (AIC) }\end{array}$ \\
\hline \multicolumn{5}{|l|}{$\begin{array}{l}\text { Two-group model: Adolescent- } \\
\text { parent interaction quality } \\
\text { (Lower Quality versus } \\
\text { Higher-Quality groups }{ }^{\mathrm{b}} \text { ) }\end{array}$} \\
\hline 0 : Basic model (equality constraint) & $46.92 * *$ & 27 & & 104.92 \\
\hline 1: Control cross-lagged paths free & 34.25 & 25 & $12.67 * *$ & 96.25 \\
\hline 2: Solicitation cross-lagged paths free & 33.26 & 23 & .99 & 99.26 \\
\hline 3: Stability paths free & 24.67 & 20 & 8.59 & 96.67 \\
\hline 4: Covariances free & 15.93 & 14 & 8.74 & 99.93 \\
\hline 5: All paths free & 13.82 & 12 & 2.11 & 101.82 \\
\hline \multicolumn{5}{|l|}{$\begin{array}{l}\text { Four-group model: Gender and } \\
\text { adolescent-parent } \\
\text { interaction quality }\end{array}$} \\
\hline 0: Basic model (equality constraint) & $92.63^{*}$ & 69 & & 178.63 \\
\hline 1: Covariances free & 55.37 & 51 & $37.26^{* *}$ & 177.37 \\
\hline $\begin{array}{l}\text { 2: Control cross-lagged paths free } \\
\text { 3: Solicitation cross-lagged }\end{array}$ & 41.99 & 45 & $13.38 *$ & 175.99 \\
\hline paths free & 40.49 & 39 & 1.50 & 186.49 \\
\hline 4: Stability paths free & 26.12 & 30 & 14.37 & 190.12 \\
\hline 5: All paths free & 17.80 & 24 & 8.32 & 193.80 \\
\hline
\end{tabular}

Note: Statistics in italics represent values for the initial, fixed models. Statistics in bold represent values for the final models.

a. All statistics represent comparisons to the preceding model.

b. Lower Quality group: Network of Relationship Inventory (NRI) score $\leq 3.521$ ( $n=153$ );

Higher Quality group: NRI score $>3.521(n=154)$.

c. Lower-Quality group Male $(n=85)$; Lower-Quality group Female $(n=68)$; Higher-Quality group $_{\text {Male }}(n=66)$; Higher-Quality group Female $(n=88)$.

$* p \leq .05$. ** $p \leq .01$.

satisfactory, $\chi^{2}(27)=23.62, p=.65, \mathrm{CFI}=1.00, \mathrm{AGFI}=.96$, root mean square error of approximation (RMSEA) $=.00$; and significant relations $(\mathrm{p}<.001)$ existed in the relative stability paths for solicitation $\left(\beta_{\text {Male }}=.46\right.$, $\left.\beta_{\text {Female }}=.36\right)$, Invasion $\left(\beta_{\text {Male }}=.43, \beta_{\text {Female }}=.44\right)$, control $\left(\beta_{\text {Male }}=.38, \beta_{\text {Female }}=\right.$ $.48)$, and the link from Wave 1 age to Wave 2 control $\left(\beta_{\text {Male }}=-.11, \beta_{\text {Female }}=\right.$ $-.12, p<.02)$. No cross-lagged paths were significant. No model improvements were noted as a result of successively freeing the equality constraints. 


\section{Figure 2}

Standardized Coefficients for Model 1 of Relationships

Between Solicitation, Control, and Privacy Invasion for Lower Quality $(n=153)$ and Higher Quality $(n=154)$ Groups

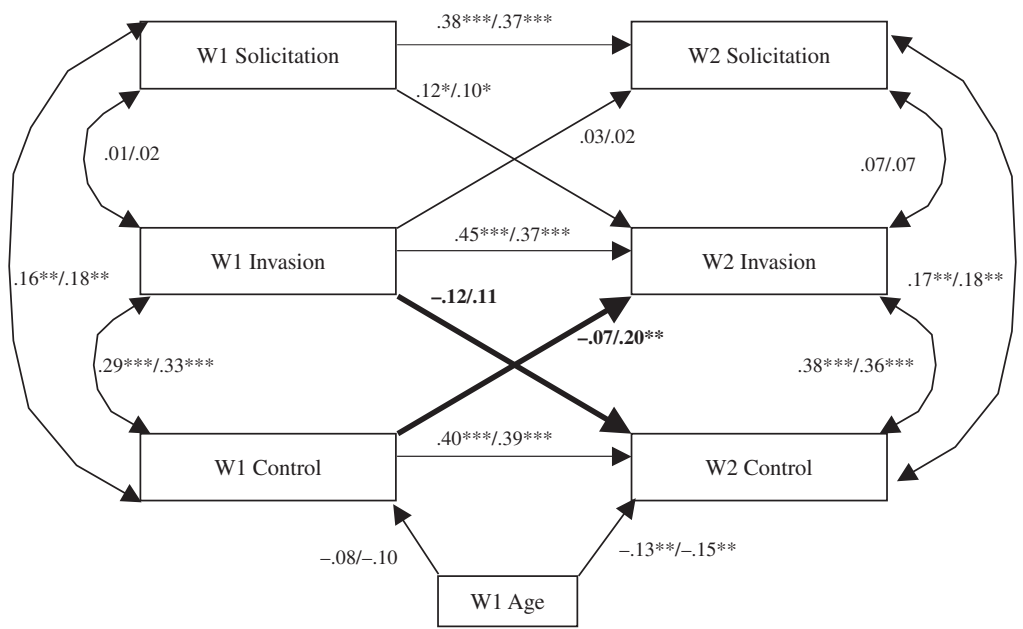

Note: Scores separated by a backslash represent Lower Quality and Higher Quality group coefficients, respectively. Coefficients and lines in bold represent significant between-groups differences. W1 and W2 indicate Wave 1 and Wave 2. $\chi^{2}(25)=34.25, p=.10$, confirmatory fit index $(\mathrm{CFI})=.97$, adjusted goodness-of-fit index $(\mathrm{AGFI})=.93$, root mean square error of approximation (RMSEA) $=.04$.

$* p \leq .05 . * * p \leq .01 . * * * p \leq .001$.

Theoretical model moderated by gender and adolescent-parent interaction quality. To explore whether the moderating effect of adolescent-parent interaction quality differed between males and females, a four-group SEM model was analyzed. Initial results suggested that, beyond the equality model (Model 0), the original order of freeing cross-paths should be altered, with covariances freed first (Model 1) and then the control crosspaths (Model 2). Since these analyses were exploratory with no hypotheses put forth, this altered order was accepted. As seen in Table 3, both Models 1 and 2 showed an improved fit over the initial model. No other changes provided further improvement, and Model 2 showed the lowest AIC value. Thus, Model 2 was retained. 
Standardized coefficients and fit indices for the model are available in Table 4. Significant group differences existed in the covariances between parental control and perceived invasion when comparing both groups of females with the Higher Quality males in Wave 1 (critical ratio $\geq 1.96, p<$ .05). All groups except Higher Quality males showed a positive association between Wave 1 reports of control and invasion. In Wave 2, all groups showed a positive correlation and no group differences were present.

Males in the Lower Quality group showed a negative correlation between solicitation and invasion in Wave 1, in contrast to all other groups (critical ratios $\geq 2.24, p<.05$ ), in that a negative correlation existed. Additionally, males in the Higher Quality group showed a positive correlation. In Wave 2, no group differences were present and a positive correlation was found only for Lower Quality males. No group differences existed for covariances between solicitation and control at either time. At each time point, only Higher Quality males showed a positive correlation.

In terms of the parental control cross-paths, males in the Lower Quality group differed significantly from both Higher Quality groups (critical ratio $\geq$ 2.06, $p<.05$ ). Lower Quality females were also different from Higher Quality males (critical ratio $=2.07, p<.05$ ). The Higher Quality males were the only group to show a significant link between parental control and feelings of privacy invasion, though there was a trend in this direction for Higher Quality females $(p=.08)$. All groups again showed significant results for the cross-lagged path from Wave 1 solicitation to Wave 2 invasion, the three stability paths, and the path from Wave 1 age to Wave 2 control.

\section{Discussion}

In the face of early adolescents' attempts at individuation from other family members, parents often try to stay informed about youth's free time activities and peer associations. They may do so either by asking questions and initiating conversations (parental solicitation) or by setting firm rules around disclosure and permission-seeking (parental control; Stattin \& Kerr, 2000). The present research investigated whether these active parental monitoring strategies contributed to adolescents' feelings of privacy invasion. We predicted that the quality of adolescent-parent interactions would moderate levels of parental monitoring (Hypothesis 1) and adolescents' reports of privacy invasion (Hypothesis 2). We also predicted longitudinal associations from parental monitoring to perceived invasion (Hypothesis 3) but again expected interaction quality to act as a moderator (Hypothesis 4). The 


\section{Table 4}

\section{Model 2 Standardized Coefficients for Four-Group Analysis (Male Versus Female and Lower Quality Versus Higher Quality) of Relationships Between Solicitation, Control, and Privacy Invasion}

\begin{tabular}{|c|c|c|c|c|}
\hline Path & $\begin{array}{c}\text { Lower } \\
\text { Quality }_{\text {Male }}\end{array}$ & $\begin{array}{c}\text { Lower } \\
\text { Quality }_{\text {Female }}\end{array}$ & $\begin{array}{c}\text { Higher } \\
\text { Quality }_{\text {Male }}\end{array}$ & $\begin{array}{c}\text { Higher } \\
\text { Quality }_{\text {Female }}\end{array}$ \\
\hline \multicolumn{5}{|l|}{ Correlations } \\
\hline $\begin{array}{l}\text { Wave } 1 \text { (W1) Control } \leftarrow \rightarrow \\
\text { W1 Invasion }\end{array}$ & $.23 *$ & $.41 * *_{a}$ & $.15_{\mathrm{a}, \mathrm{b}}$ & $.41 * * *_{b}$ \\
\hline $\begin{array}{l}\text { Wave } 2 \text { (W2) Control } \leftarrow \rightarrow \\
\text { W2 Invasion }\end{array}$ & $.43 * * *$ & $.32 *$ & $.34 * *$ & $.39 * * *$ \\
\hline $\begin{array}{l}\text { W1 Solicitation } \leftarrow \rightarrow \\
\text { W1 Invasion }\end{array}$ & $-.31 *_{a, b, c}$ & $.07 \mathrm{a}$ & $.25_{\mathrm{b}}$ & $.10_{\mathrm{c}}$ \\
\hline $\begin{array}{l}\text { W2 Solicitation } \leftarrow \rightarrow \\
\text { W2 Invasion }\end{array}$ & $.23 *$ & -.03 & -.07 & .14 \\
\hline $\begin{array}{l}\text { W1 Solicitation } \leftarrow \rightarrow \\
\text { W1 Control }\end{array}$ & .12 & .03 & $.35 * *$ & .17 \\
\hline $\begin{array}{l}\text { W2 Solicitation } \leftarrow \rightarrow \\
\text { W2 Control }\end{array}$ & .11 & .23 & $.31 *$ & .03 \\
\hline \multicolumn{5}{|l|}{ Cross-lagged paths } \\
\hline W1 Control $\rightarrow$ W2 Invasion & $-.09_{\mathrm{a}, \mathrm{b}}$ & $-.05_{\mathrm{c}}$ & $.24 *_{\mathrm{a}, \mathrm{c}}$ & $.15 \dagger_{\mathrm{b}}$ \\
\hline W1 Invasion $\rightarrow$ W2 Control & $-.14_{\mathrm{a}}$ & -.07 & $.16_{\mathrm{a}}^{\alpha, \mathrm{c}}$ & .07 \\
\hline $\begin{array}{l}\text { W1 Solicitation } \rightarrow \\
\text { W2 Invasion }\end{array}$ & $.13^{*}$ & $.12 *$ & $.12^{*}$ & $.10^{*}$ \\
\hline $\begin{array}{l}\text { W1 Invasion } \rightarrow \\
\text { W2 Solicitation }\end{array}$ & .02 & .02 & .01 & .02 \\
\hline \multicolumn{5}{|l|}{ Relative stability paths } \\
\hline W1 Invasion $\rightarrow$ W2 Invasion & $.47 * * *$ & $.44 * * *$ & $.30 * * *$ & $.42 * * *$ \\
\hline W1 Control $\rightarrow$ W2 Control & $.37 * * *$ & $.52 * * *$ & $.35 * * *$ & $.45 * * *$ \\
\hline $\begin{array}{l}\text { W1 Solicitation } \rightarrow \\
\text { W2 Solicitation }\end{array}$ & $.43 * * *$ & $.31 * * *$ & $.39 * * *$ & $.33 * * *$ \\
\hline \multicolumn{5}{|l|}{ Age paths } \\
\hline W1 Age $\rightarrow$ W1 Control & -.09 & -.07 & -.10 & -.09 \\
\hline W1 Age $\rightarrow$ W2 Control & $-.11 * *$ & $-.11 * *$ & $-.11 * *$ & $-.14 * *$ \\
\hline
\end{tabular}

Note: Values within a row with the same subscripts represent statistically significant differences between the groups $(p<.05) . \chi^{2}(45)=41.99, p=.60$, confirmatory fix index $(\mathrm{CFI})=1.00$, adjusted goodness-of-fit index $(\mathrm{AGFI})=.91$, root mean square error of approximation (RMSEA) $=.00$.

a. Lower Quality Male $(n=85)$; Lower Quality Female $(n=68)$; Higher Quality Male $(n=$ 66); Higher Quality Female $(n=88)$.

${ }^{\dagger} p<.08 .{ }^{*} p<.05 .{ }^{* *} p<.01 .{ }^{*} * * p<.001$. 
obtained results shed new light on adolescents' interpretations of specific parental monitoring behaviors.

Supporting Hypothesis 1, lower quality adolescent-parent interactions were associated with less parental solicitation and control (see also Kerr \& Stattin, 2000). Additionally, levels of parental solicitation remained consistent over time, but parental control decreased with age. In line with prior studies (Kerr \& Stattin, 2000; Smetana \& Daddis, 2002), females reported more solicitation and control over the 2-year period, and males reported stronger reductions in control. In other words, parents consistently requested information (solicitation) but reduced overt rules about disclosure (parental control) for males. The decline in control was modest, however, and major reductions may not occur until later in adolescence (Collins et al., 1997; Smetana et al., 2006).

Perceived invasion was higher in the Lower Quality group, in line with Hypothesis 2. These findings suggest an association between higher privacy boundary turbulence and lower relationship satisfaction (Petronio, 1994, 2002), although the direction of these influences is still unclear. Parental control was not associated with later invasion perceptions in this group, however, and solicitation showed only a modest relationship. Issues of statistical power could have masked these associations to some extent, especially if the Lower Quality group was actually made up of two or more types of families with different parenting processes. Furthermore, adolescents who have problematic relations with parents may not respond honestly to solicitations or comply with disclosure rules, and parents may not trust them to do so (Kerr et al., 1999; Kerr \& Stattin, 2003). These suspicions could lead to parents' use of tactics not addressed in the solicitation and control scales, such as snooping or eavesdropping (McKinney, 1998; Petronio, 1994). This interpretation might also explain why the Lower Quality group showed a (nonsignificant) negative association from invasion in Wave 1 to parental control in Wave 2, while the Higher Quality group trended toward a positive relation. Additionally, invasion perceptions decreased over time across groups, perhaps denoting adolescents' expansion of privacy boundaries (Parke \& Sawin, 1979; Petronio, 1994) and parents' gradual relinquishing of boundary ownership (Collins et al., 1997; Smetana et al., 2006). This may have occurred either through successful negotiations of changing privacy rules or through parents' reducing their involvement in reaction to adolescents' perceived concealment or deception (Finkenauer, Frijns, Engels, \& Kerkhof, 2005).

The data did not confirm our expectation for parental solicitation and control to predict later feelings of privacy invasion for adolescents as a whole 
(Hypothesis 3), although correlations between control and invasion were significant at each measurement wave. CPM theory proposes that feelings of privacy invasion arise when individuals hold conflicting expectations about controlling personal information. We predicted that adolescents reporting higher quality interactions with parents would demonstrate stronger relationships between both types of parental monitoring and perceived invasion, because they would expect more control over their informational boundaries (Hypothesis 4). This hypothesis received mixed support.

In contrast to the expectations of Hypothesis 4, parental solicitation predicted later invasion perceptions for both Lower and Higher Quality groups. The direct nature of solicitations, which often require immediate responses, may foster feelings of invasion more consistently than standing disclosure rules that rely upon adolescents' continued compliance. In line with Hypothesis 4, only the Higher Quality group showed a longitudinal association from parental control to perceived invasion. Moderating the model further by gender revealed that this association was particularly attributable to males.

Only Higher Quality males reported a co-occurrence of parental solicitation and control at either time point. Higher Quality males seemed to get a "double dose" of monitoring, and may have judged the combination to be excessive. Furthermore, this group showed a correlation between parental solicitation and invasion only in Wave 1 and between parental control and invasion only in Wave 2. Higher Quality males may have initially accepted firm disclosure rules but might have gradually come to view solicitation as an alternative that allowed them greater boundary control. If they began to reject parental control and attempted to negotiate new standards, this could explain the greater reduction in this monitoring strategy for males, compared to females.

The gender differences in levels of parental monitoring and reactions to parental control suggest a double standard in the monitoring of male versus female adolescents. Consistent with traditional gender roles, parents may believe that male adolescents require more autonomy. Relatedly, Higher Quality males' greater autonomy expectations may explain their stronger reactions to parental control. They may have felt parents deserved information, yet still desired control over disclosures (Smetana et al., 2006) and felt they had earned such a right by nature of their positive relations. At the same time, these good relationships created pressures for communication (Laird et al., 2003; Smetana et al., 2006). This interpretation highlights the dialectical tension between openness and closedness, suggested by CPM theory to be central to privacy negotiations (Petronio, 2002). This tension was more apparent for Higher Quality males, presumably because of 
greater pressures for open communication in combination with stronger expectations for information control.

Also in line with gender norms, parents could have expected that females would more willingly disclose (Petronio, 2002), and so were more comfortable in seeking information. Accordingly, females showed no correlations between solicitation and invasion, and Higher Quality females showed only a trend toward a longitudinal association between parental control and invasion. Males and females thus seemed to differently define the rules about information co-ownership with parents (Petronio, 2002), with females' boundaries being more permeable to parents' attempts at access.

This study elaborates upon the issue of parental privacy invasion by using an early adolescent sample, uncommon in past investigations, and is also the first to link Petronio's (2002) general CPM theory with Kerr and Stattin's (e.g., 2000) reinterpretation of parental monitoring. The findings challenge a general supposition that supportive relationships will always promote adolescents' positive interpretations of parental monitoring. Though prior research has noted a positive association between relationship satisfaction and adolescents' beliefs that parents should have information about their lives (Laird et al., 2003), youth do not necessarily evaluate specific parental monitoring activities in an equally positive way. Thus, the current investigation reiterates the importance of operationalizing parental monitoring in terms of discrete behaviors, instead of parents' resulting knowledge (Kerr \& Stattin, 2000; Stattin \& Kerr, 2000).

With regard to measurement, the results of the CFAs highlight the need to reassess scales of parenting practices in different cultures. The research also identified a useful measure of adolescents' feelings of privacy invasion. The narrower focus on privacy issues in the LEE Intrusiveness subscale was preferable over other potential measures of invasion perceptions, as it is less conflated with psychological control techniques (cf. Barber, 1996) or losing behavioral autonomy (cf. Kerr \& Stattin, 2000). Using this new measure, the study supports and extends prior findings on the problems associated with various forms of parental control (Barber, 1996; Kerr \& Stattin, 2000).

Several caveats still exist in the present study. The use of self-report data presents a one-sided story, though others have argued for the primacy of adolescents' reports about their own thoughts and feelings regarding "unpleasant aspects of the relationship" with parents (Laursen \& Collins, 2004, p. 341). The phenomenological nature of privacy boundaries also necessitated that preference be given to adolescents' own views (Laufer \& Wolfe, 1977; Petronio, 2002). Common method variance is also a threat to 
self-report validity. The group differences reported for parental control seem robust to this argument, however, as the effect would have to be different in the two groups. This seems improbable, since adolescents' reports on interaction quality were completed separately from other scales. Even so, negotiations around privacy are dynamic in nature (Petronio, 2002), and a multiple-informant approach would be useful for examining parent-versus child-driven effects (e.g., Kerr \& Stattin, 2003).

Issues of sample size and statistical power limited the ability to examine the moderating role of adolescent-parent interaction quality. Most adolescents had fairly positive interactions with parents, requiring the use of a median split. Thus, the terms higher and lower described these groups in a relative sense. A larger sample would allow the use of interaction quality as a continuous moderator in SEM. Furthermore, additional measurement waves would allow for greater confidence about causal inference from manifest variables and would shed light on the normative pattern of change over time.

Adolescents reported on parents as a unit, but mother-father distinctions could be important. Mothers may have closer relationships with adolescents (Steinberg \& Silk, 2002) and be more active in efforts to learn about children's activities (Waizenhofer et al., 2004). It is also unclear whether the findings extend to families of other ethnic (e.g., Turkish or Moroccan) or socioeconomic backgrounds in the Netherlands. Though we would expect similar results in other cultures that value the development of autonomy in adolescence, recent research suggests that youth and parents disagree over privacy boundaries even in cultures that traditionally emphasize collectivism and stronger family cohesion (Tang \& Dong, 2006). More cross-cultural investigations that directly examine privacy invasion in families are needed.

In conclusion, the present results support Kerr and Stattin's (2000) contentions that adolescents may interpret parental solicitation and control negatively. Issues of privacy and information control probably will arise in most adolescent-parent relationships (Petronio, 1994), and renegotiating these boundaries likely contributes to the development of realistic expectations about adolescent autonomy and disclosure (Collins \& Luebker, 1994). The results also extend Kerr and Stattin's propositions about parental control by suggesting that parents who have highly positive interactions with adolescents should use overt, steadfast disclosure rules with caution. Parents who trust their adolescents to disclose voluntarily and responsibly might consider making this good faith explicitly known, and contemplate the use of information-gathering strategies that afford teenagers a sense of control in sharing aspects of their personal lives. 


\section{Notes}

1. One reviewer suggested on conceptual grounds that these two items be removed from the Solicitation scale. The primary interest of the research concerned direct questioning of adolescents by parents, but these items did not specifically refer to whether parents were seeking information about their adolescents from third parties.

2. The improvements in Akaike information criterion (AIC) values for both Wave 1 (from 42.02 to 36.73 ) and Wave 2 (from 43.30 to 40.76 ) additionally contributed to the acceptance of a two-factor model.

\section{References}

Arbuckle, J. L. (2003). Amos 5.0.1. Chicago: SmallWaters Corp.

Barber, B. K. (1996). Parental psychological control: Revisiting a neglected construct. Child Development, 67, 3296-3319.

Burgoon, J. K., Parrott, R., LePoire, B. A., Kelley, D. L., Walther, J. B., \& Perry, D. (1989). Maintaining and restoring privacy through communication in different types of relationships. Journal of Social and Personal Relationships, 6, 131-158.

Caughlin, J. P., \& Petronio, S. (2004). Privacy in families. In A. L. Vangelisti (Ed.), Handbook of family communication (pp. 379-411). Mahwah, NJ: Lawrence Erlbaum.

Collins, W. A., Laursen, B., Mortensen, N., Luebker, C., \& Ferreira, M. (1997). Conflict processes and transitions in parent and peer relationships: Implications for autonomy and regulation. Journal of Adolescent Research, 12, 178-198.

Collins, W. A., \& Luebker, C. (1994). Parent and adolescent expectancies: Individual and relational significance. New Directions for Child Development, 66, 65-80.

Finkenauer, C., Engels, R., Branje, S., \& Meeus, W. (2003). Disclosure and relationship satisfaction in families. Journal of Marriage and the Family, 66, 195-209.

Finkenauer, C., Frijns, T., Engels, R. C. M. E., \& Kerkhof, P. (2005). Perceiving concealment in relationships between parents and adolescents: Links with parental behavior. Personal Relationships, 12, 387-406.

Furman, W., \& Buhrmester, D. (1985). Children's perceptions of the personal relationship in their social networks. Developmental Psychology, 21, 1016-1024.

Hale, W. W., III, Raaijmakers, Q., Gerlsma, C., \& Meeus, W. (2007). Psychometric properties of the Level of Expressed Emotion (LEE) questionnaire for adolescents from the general population. Journal of Social Psychiatry and Psychiatric Epidemiology, 42, 215-220.

Hunter, F. T. (1985). Adolescents' perceptions of discussions with parents and friends. Developmental Psychology, 20, 1092-1099.

Jöreskog, K. G., \& Sörbom, D. (1989). Lisrel 7. Chicago: SPSS.

Kerr, M., \& Stattin, H. (2000). What parents know, how they know it, and several forms of adjustment: Further support for a reinterpretation of monitoring. Developmental Psychology, 36, 366-380.

Kerr, M., \& Stattin, H. (2003). Parenting of adolescents: Action or reaction? In A. C. Crouter \& A. Booth (Eds.), Children's influence on family dynamics: The neglected side of family relationships (pp. 121-151). Mahwah, NJ: Lawrence Erlbaum.

Kerr, M., Stattin, H., \& Trost, K. (1999). To know you is to trust you: Parents' trust is rooted in child disclosure of information. Journal of Adolescence, 22, 737-752. 
Laird, R. D., Pettit, G. S., Dodge, K. A., \& Bates, J. E. (2003). Change in parents' monitoring knowledge: Links with parenting, relationship quality, adolescent beliefs, and antisocial behavior. Social Development, 12, 401-419.

Larson, R. W., Richards, M. H., Moneta, G., Holmbeck, G., \& Duckett, E. (1996). Changes in adolescents' daily interaction with their families from ages 10 to 18: Disengagement and transformation. Developmental Psychology, 32, 744-754.

Laufer, R. S., \& Wolfe, M. (1977). Privacy as a concept and a social issue: A multidimensional developmental theory. Journal of Social Issues, 33, 22-41.

Laursen, B., \& Collins, W. A. (2004). Parent-child communication during adolescence. In A. L. Vangelisti (Ed.), Handbook of family communication (pp. 333-348). Mahwah, NJ: Lawrence Erlbaum.

McKinney, K. D. (1998). Space, body, and mind: Parent's perceptions of children's privacy needs. Journal of Family Issues, 19, 75-100.

Margulis, S. T. (2003). Privacy as a social issue and behavioral concept. Journal of Social Issues, 59, 243-261.

Newell, P. B. (1995). Perspectives on privacy. Journal of Environmental Psychology, 15, 87-104.

Parke, R. D., \& Sawin, D. B. (1979). Children's privacy in the home: Developmental, ecological, and child-rearing determinants. Environment and Behavior, 11, 87-104.

Petronio, S. (1994). Privacy binds in family interactions: The case of parental privacy invasion. In W. R. E. Cupach \& B. H. E. Spitzberg (Eds.), The dark side of interpersonal communication (pp. 241-257). Hillsdale, NJ: Lawrence Erlbaum.

Petronio, S. (2002). Boundaries of privacy: Dialectics of disclosure (SUNY Series in Communication studies). Albany: State University of New York Press.

Pomerantz, E. M., \& Eaton, M. M. (2000). Developmental differences in children's conceptions of parental control: "They love me, but they make me feel incompetent." MerrillPalmer Quarterly, 46, 140-167.

Pomerantz, E. M., \& Ruble, D. N. (1998). The multidimensional nature of control: Implications for the development of sex differences in self-evaluation. In J. Heckhausen \& C. Dweck (Eds.), Motivation and self-regulation across the life span (pp. 159-184). New York: Cambridge University Press.

Raaijmakers, Q. A. W. (1999). Effectiveness of different missing data treatments in surveys with Likert-type data: Introducing the relative mean substitution approach. Educational and Psychological Measurement, 59, 725-748.

Smetana, J. G., \& Daddis, C. (2002). Domain-specific antecedents of parental psychological control and monitoring: The role of parenting beliefs and practices. Child Development, $73(2), 563-580$.

Smetana, J. G., Metzger, A., Gettman, D. C., \& Campione-Barr, N. (2006). Disclosure and secrecy in adolescent-parent relationships. Child Development, 77, 201-217.

Stattin, H., \& Kerr, M. (2000). Parental monitoring: A reinterpretation. Child Development, 71(4), 1072-1085.

Steinberg, L. (2002). Adolescence (6th ed.). Boston: McGraw-Hill.

Steinberg, L., \& Silk, J. S. (2002). Parenting adolescents. In M. H. Bornstein (Ed.), Handbook of parenting: Vol. 1. Children and parenting (pp. 103-133). Mahwah, NJ: Lawrence Erlbaum.

Tang, S., \& Dong, X. (2006). Parent's and children's perceptions of privacy rights in China: A cohort comparison. Journal of Family Issues, 27, 285-300.

Waizenhofer, R. N., Buchanan, C. M., \& Jackson-Newsom, J. (2004). Mothers' and fathers' knowledge of adolescents' daily activities: Its sources and its links with adolescent adjustment. Journal of Family Psychology, 18, 348-360. 
Wolfe, M., \& Laufer, R. (1974). The concept of privacy in childhood and adolescence. In S. Margulis (Ed.), Privacy (pp. 29-54). Stony Brook, NY: Environmental Design Research. Youniss, J., \& Smollar, J. (1985). Adolescent relations with mothers, fathers, and friends. Chicago: University of Chicago Press.

Skyler T. Hawk is currently a doctoral researcher in the Department of Social Psychology at the University of Amsterdam. He received a master of science degree from the Development and Socialization in Childhood and Adolescence (DaSCA) International Masters Program at Utrecht University and a master of arts degree in psychology from the University of Hawaii. His major interests concern emotion and social cognition, privacy and disclosure issues in close relationships, and adolescent autonomy development.

William W. Hale III, $\mathrm{PhD}$, is a clinical psychologist and an assistant professor in the department of Child and Adolescent Studies at Utrecht University. Currently, he is involved in research on adolescent depression and anxiety and the effects of peer and parental factors on these pathologies.

Quinten A. W. Raaijmakers, PhD, is an associate professor at the Department of Child and Adolescent Studies at Utrecht University. His research interests include moral and political identity of adolescents and adolescent problem behaviors.

Wim Meeus, $\mathrm{PhD}$, is a full professor of adolescent development at Utrecht University. Research interests include identity development, personality, and social relationships in adolescence. 